\title{
Modified Lateral Pressure Formula of Shallow and Circular Silo Considering the Elasticities of Silo Wall and Storage Materials
}

Zhijun Xu ( $\boldsymbol{D}$ xuzhijun@haut.edu.cn )

Henan University of Technology

Pengfei Liang

Henan University of Technology

\section{Research Article}

Keywords: shallow and circular silo, lateral pressure, elastic deformation, Modified method, Rankine formulation, Janssen formulation

Posted Date: December 28th, 2021

DOI: https://doi.org/10.21203/rs.3.rs-1190512/v1

License: (c) (i) This work is licensed under a Creative Commons Attribution 4.0 International License.

Read Full License 


\title{
1 Modified Lateral Pressure Formula of Shallow and Circular Silo
}

\section{Considering the Elasticities of Silo Wall and Storage Materials}

\author{
Zhijun $\mathrm{Xu}^{{ }^{1 *}}$ \& Pengfei Liang ${ }^{1}$
}

\author{
${ }^{1}$ Henan Key Laboratory of Grain and oil Storage Facility \& Safety, Henan University of Technology, \\ Zhengzhou450001, China. *e-mail: xuzhijun@ @aut.edu.cn
}

\begin{abstract}
For the shallow and circular silo(SCS), when the aspect ratio is between 1.0 and 1.5, the lateral pressure especially dynamic pressure may cause destruction if the size of the silo is large. In general, the lateral pressures should be calculated simultaneously according to the shallow silo and the deep silo calculation formulas based on Rankine's earth pressure theory and Janssen's theory, respectively, and the larger value of them should be adopted. However, whether the two formulas are reasonable needs to be verified. This paper proposed a modified calculation method of lateral pressure on the silo wall of SCS, considering the elasticities of silo wall and storage materials. The availability of shallow silo and deep silo methods, and the modified method were compared with the experiment and simulation. The results show that the Rankine's formula is too conservative for the static lateral pressure, and the results of the modified method and Janssen formula are close to that of the experimental and simulation. For the dynamic lateral pressure calculation, Rankine theory is unsafe for the discharging load. The relative error of the dynamic lateral pressure based on Janssen theory is between $20 \%$ and $30 \%$, which is too large. The dynamic lateral pressure calculated by the modified method is in good agreement with that of the experimental and simulation, and the relative error is less than $10 \%$. Therefore, the modified method of lateral pressure formula is reasonable, which can provide guidance for the safety design of silo structure.
\end{abstract}

Keywords: shallow and circular silo; lateral pressure; elastic deformation; Modified method; Rankine formulation; Janssen formulation

\section{Introduction}

The characteristics of the silo are large storage, easy mechanization, reasonable mechanics and good anti-seismic performance[1], which is widely used in grain engineering, chemical engineering, coal engineering, and so on. Especially in China, about one-third of the grain storage structures use silos. Therefore, the safety of the silo is important. It is widely known that concentric discharging at the silo bottom is the most desirable discharging way[2-5]. The idea that the dynamic pressure on the sidewall is greater than the static pressure during concentric discharging has been generally accepted, which may cause the silo's structural failure and affect the stability of bulk solid handling. Although the silo structure is relatively simple, the storage material is an interactive particle aggregation with complex mechanical properties of solid and liquid. Therefore, the dynamic pressure is the main consideration for the design of the silo. For shallow and circular silo (SCS), when the aspect ratio is between 1.0 and 1.5, the lateral pressure especially the dynamic pressure may destroy the silo if the silo size is large[6,7]. For example, a bolted steel silo which can store 9000 tons coal ash collapsed after first been filled to capacity, and the reason is that the pressure on the silo wall is not understood before design[7]. For the silo with aspect ratio between 1.0 and 1.5, according to silo specification, the lateral pressure on the silo wall should be calculated simultaneously according to the formulas of the shallow silo and the deep silo based on Rankine's earth pressure theory and 
Janssen's theory, respectively, and the maximum value calculated by the above two methods should be adopted[8,9]. However, Rankine's formula regards the silo wall as smooth, ignoring the friction between bulk material and silo wall, and Janssen's formula regards the silo as infinite depth and fails to take into account the influence of silo bottom on lateral pressure. Therefore, it is necessary to modify the lateral pressure of SCS whose aspect ratio is between 1.0 and 1.5.

The silo structure designers believe that the pressure of storage materials in the silo is similar to the fluid pressure based on the traditional hydrodynamics theory. That is, the pressure is linearly distributed in the height direction, and its value is consistent with the liquid pressure, which is only related to the height and density of storage materials[10,11]. However, the storage materials are large numbers of particle aggregates, and their mechanical properties are extremely complex, which is difficult to reasonably estimate using the traditional classical mechanics theory and condensed matter physics theory[12]. In recent years, relevant scholars have found that the maximum dynamic pressure on the silo wall is often several times of the static pressure during silo discharging[13-16]. Thus, if the dynamic pressure on silo wall is not considered during the design process, it will lead to the instability of the silo.

Many scholars have paid attentions to the complex dynamic lateral pressure on the silo wall [17-20]. Horabik et al[17] studied the mechanical properties of granular materials and their effects on load distribution and discussed the evolution of the constitutive model of granular materials under the mechanical framework. Patel et al[18] utilized FEM to analyze the positive pressure, vertical pressure, circumferential stress and longitudinal stress on silo wall under different boundary conditions, considering Drucker-Prager criterion and material properties. Lei et al[19] established a new theoretical model of lateral pressure on the silo wall and put forward the empirical expression of stress state transition between quasi-static fluid and quasiJanssen fluid. An et al[20] studied the normal stress characteristics on silo wall by arranging pressure sensors to measure dynamic lateral stress. Unfortunately, the above investigations do not consider the influences of storage materials and silo deformation. As a matter of fact, most silos are made of materials with small stiffness, such as metallic plate silos[21,22]. Therefore, when calculating the lateral pressure on the silo wall, it is particularly important to consider the elastic deformations of silo wall and storage material.

In view of this, this paper proposed a modified calculation method of lateral pressure on the silo wall with aspect ratio between 1.0 and 1.5, considering the deformations of silo wall and storage material, which is verified through experimental results and numerical simulation.

\section{Derivation formula of lateral pressure on the silo wall}

\subsection{Janssen's formula and Rankine's formula}

Silos are usually used to store bulk materials such as grains, coals and chemicals. Therefore, the pressure theory of silo structure is based on fluid mechanics. It is considered that the lateral pressure of silo is the same as the fluid pressure, which is only related to the storage density and height and varies linearly with the height $[10,11]$. However, as a certain number of particle aggregates, granular materials have complex mechanical properties, which are different from the mechanical characteristics of fluid and solid in the traditional sense. After found this, relevant scholars made appropriate adjustments to the research direction and achieved significant results in granular mechanics. Based on the static equilibrium principle existing in the granular micro-element of bulk storage, Janssen deduced the static lateral pressure on deep silo, which is the reference basis for most national silo design specifications. The pressure on the silo wall calculated by Janssen's formula is[9]: 


$$
P_{\mathrm{h}}=C_{\mathrm{h}} \gamma \rho\left(1-e^{-\mu \mathrm{k} s / \rho}\right) / \mu
$$

where $\mu$ is the friction coefficient between the storage materials and silo wall, $\rho$ the hydraulic radius of horizontal net section of silo, $s$ the distance from top surface or cone center of gravity to calculated section, $C_{\mathrm{h}}$ the correction coefficient of horizontal pressure on the silo. When $C_{\mathrm{h}}$ equals 1.0, Eq. (1) is applicable for the static lateral pressure calculation. While, for the dynamic lateral pressure calculation, $C_{\mathrm{h}}$ is larger than 1.0 .

Rankine's formula is based on the earth pressure theory to predict the static lateral pressure of shallow silo, which is[9]:

$$
P_{\mathrm{h} 1}=\mathrm{k} \gamma \mathrm{s}
$$

where $\gamma, \mathrm{s}$ and $\mathrm{k}$ are the gravity density $\left(\mathrm{kN} / \mathrm{m}^{3}\right)$, height $(\mathrm{m})$, and lateral pressure coefficient of storage material, respectively.

The expression of $\mathrm{k}$ in Eq. (2) is:

$$
\mathrm{k}=\tan ^{2}(45-\varphi / 2)
$$

where $\varphi$ is the angle of internal friction of storage materials.

For above two methods, Rankine's formula ignores the friction between granular material and silo wall, and Janssen's formula fails to take into account the influence of silo bottom on lateral pressure. At the same time, both the two formulas regard the lateral pressure coefficients as invariant constants. However, in reallife situations, the lateral pressure coefficient varies with the depths of the silo. Therefore, the above two methods for determining the lateral pressure of shallow silo between 1.0 and 1.5 are not reasonable.

\subsection{Modification of lateral pressure on the silo wall}

According to above analysis, both Rankine's formula for shallow silo and Janssen's formula for deep silo do not consider the elastic deformations of the silo and storage materials. According to the theory of plate and shell, the membrane force deforms the silo wall, and the bending moment is almost "zero". At the bottom of silo, due to the "edge effect", the bending moment is obvious, when subjected to the action of granular particles[23]. According to the generalized Hooke's theorem, the stresses in the circumferential, axial and radial directions will affect the circumferential strain. The granular particles near the silo wall are selected as the unit for stress analysis, as shown in Fig.1.

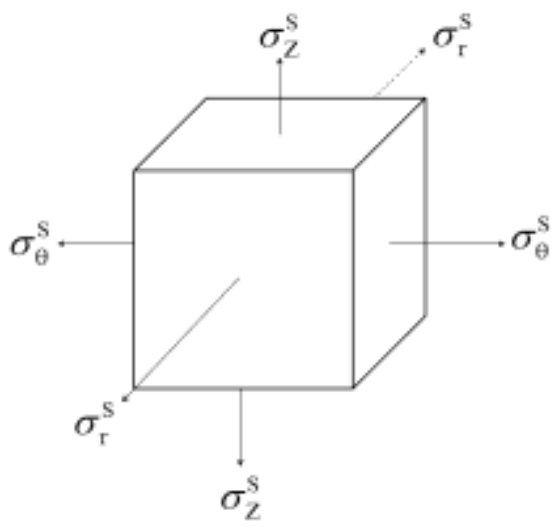

Fig. 1. The stress diagram of microelement of storage materials. 
110 the material stored near the silo wall. The circumferential strain $\left(\varepsilon_{\theta}^{\mathrm{S}}\right)$ of storage materials is:

$$
\varepsilon_{\theta}^{\mathrm{S}}=\frac{1}{E_{\mathrm{S}}}\left[\sigma_{\theta}^{\mathrm{S}}-v_{\mathrm{S}}\left(\sigma_{\mathrm{r}}^{\mathrm{S}}+\sigma_{\mathrm{Z}}^{\mathrm{S}}\right)\right]
$$

111 where $\sigma_{\theta}^{\mathrm{S}}, \sigma_{\mathrm{r}}^{\mathrm{S}}$ and $\sigma_{\mathrm{Z}}^{\mathrm{S}}$ are the circumferential stress, radial stress and axial stress, respectively, $E_{\mathrm{S}}$

and $v_{\mathrm{S}}$ are the Elastic Modulus and Poisson's ratio of storage materials, respectively.

Since the pressure of storage materials on the silo wall is mainly membrane force, the bending moment is "zero". According to the elastic mechanics theory, the stress is positive when the storage materials is pulled and is negative when the storage materials is pushed[24]. The axial stress of the element is the negative value of the gravity of storage materials $\left(P_{\mathrm{V}}\right)$. The radial stress $\left(\sigma_{\mathrm{r}}^{\mathrm{S}}\right)$ and circumferential stress $\left(\sigma_{\theta}^{\mathrm{S}}\right)$ are both equal to the negative values of the lateral pressure $\left(P_{\mathrm{H}}\right)$, as shown in Fig. 2.

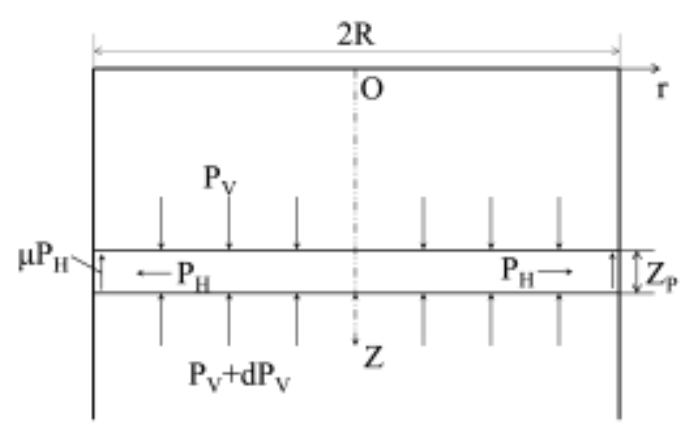

(a)

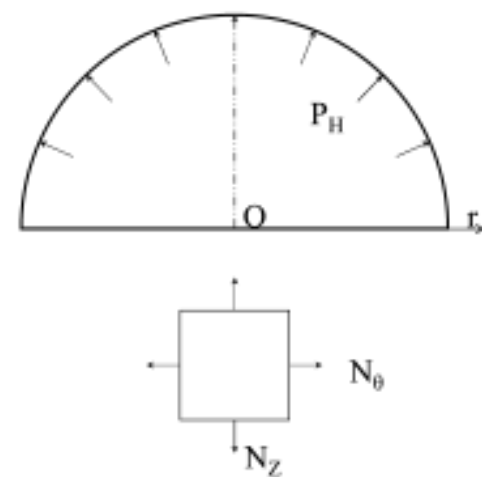

(b)

Fig. 2. Stress analysis. (a) the storage materials granular particles and (b) the silo wall. The radial stress and circumferential stress are

$$
\sigma_{\mathrm{r}}^{\mathrm{S}}=\sigma_{\theta}^{\mathrm{S}}=-P_{\mathrm{H}}
$$

$$
\sigma_{\mathrm{Z}}^{\mathrm{S}}=-P_{\mathrm{V}}
$$

Substituting Eqs. $(5,6)$ into Eq. (4) yields:

$$
\varepsilon_{\theta}^{\mathrm{S}}==\frac{1}{E_{\mathrm{S}}}\left[v_{\mathrm{S}} P_{\mathrm{v}}+\left(v_{\mathrm{S}}-1\right) P_{\mathrm{H}}\right]
$$

According to the theory of plate and shell, the membrane forces $\left(N_{\mathrm{Z}}\right.$ and $\left.N_{\theta}\right)$ are:

$$
N_{\mathrm{Z}}=\sigma_{\mathrm{Z}}^{\mathrm{W}} t, N_{\theta}=\sigma_{\theta}^{\mathrm{W}} t
$$

where $t$ is the thickness of silo wall.

Taking the semi-circular ring of silo wall as the research object, the equilibrium equations in vertical direction and horizontal direction are: 


$$
\begin{gathered}
N_{\theta}=P_{\mathrm{H}} R \\
N_{\mathrm{Z}}=-\int_{0}^{\mathrm{Z}} \mu P_{\mathrm{H}} d Z
\end{gathered}
$$

In addition, according to the theory of plate and shell, the circumferential strain is:

$$
\varepsilon_{\theta}^{\mathrm{W}}=\frac{1}{E_{\mathrm{W}}}\left[\sigma_{\theta}^{\mathrm{W}}-v_{\mathrm{W}} \sigma_{\mathrm{Z}}^{\mathrm{W}}\right]=\frac{1}{E_{\mathrm{W}} t}\left[N_{\theta}-v_{\mathrm{W}} N_{\mathrm{Z}}\right]
$$

Since the circular silo is an axisymmetric structure, circumferential strain can be calculated as:

$$
\varepsilon_{\theta}=u_{\mathrm{r}} / r
$$

where $u_{\mathrm{r}}$ is radial displacement.

Because the radial deformation of the silo wall is the same as that of the granular particles near silo wall, the strains are the same for the silo wall and the granular particles, which yields

$$
u_{\mathrm{r}}^{\mathrm{W}}=u_{\mathrm{r}}^{\mathrm{S}}, \quad \varepsilon_{\theta}^{\mathrm{W}}=\varepsilon_{\theta}^{\mathrm{S}}
$$

Based on Eq. (7) and Eq. (11), the following equals is satisfied:

$$
\frac{1}{E_{\mathrm{S}}}\left[v_{\mathrm{S}} \mathrm{P}_{\mathrm{V}}+\left(v_{\mathrm{S}}-1\right) P_{\mathrm{H}}\right]=\frac{1}{E_{\mathrm{W}} t}\left[N_{\theta}-v_{\mathrm{W}} N_{\mathrm{Z}}\right]
$$

Substituting Eq. (9) and Eq. (10) into Eq. (14), one can obtain that:

$$
v_{\mathrm{S}} P_{\mathrm{V}}=\left(1-v_{\mathrm{S}}+\frac{E_{\mathrm{S}} R}{E_{\mathrm{W}} t}\right) P_{\mathrm{H}}+\frac{E_{\mathrm{S}} R}{E_{\mathrm{W}} t} \times \frac{\mu v_{\mathrm{W}}}{R} \int_{0}^{\mathrm{Z}} P_{\mathrm{H}} d \mathrm{Z}
$$

where $\eta=E_{\mathrm{S}} R / E_{\mathrm{W}} t$ is the stiffness ratio, and $v_{\mathrm{w}}$ is a constant less than 1.0. For general metallic silos, the range of stiffness ratio lies between 0.01 and 0.2 .

Dividing both sides of Eq. (15) by $P_{\mathrm{H}}$, simultaneously, the second term on the right side of Eq. (15) is approximately zero, and Eq. (14) can be rewritten as:

$$
\mathrm{k}_{1}=\frac{\mathrm{P}_{\mathrm{H}}}{\mathrm{P}_{\mathrm{v}}}=\frac{v_{\mathrm{S}}}{1-v_{\mathrm{S}}+\eta}
$$

Eq. (16) is the correction coefficient of lateral pressure considering the elasticity of silo wall.

For the concrete silo with rigid wall, assuming that the granular particles in the silo are elastic and axisymmetric, the stress-strain relationship of the silo is: 


$$
\left[\begin{array}{l}
\sigma_{\mathrm{r}}^{\mathrm{S}}=\Delta\left(\varepsilon_{\mathrm{r}}^{\mathrm{S}}+\frac{v}{1-v_{\mathrm{S}}} \varepsilon_{\theta}^{\mathrm{S}}+\frac{v}{1-v_{\mathrm{S}}} \varepsilon_{\mathrm{Z}}^{\mathrm{S}}\right) \\
\sigma_{\theta}^{\mathrm{S}}=\Delta\left(\frac{v}{1-v_{\mathrm{S}}} \varepsilon_{\mathrm{r}}^{\mathrm{S}}+\varepsilon_{\theta}^{\mathrm{S}}+\frac{v_{\mathrm{S}}}{1-v_{\mathrm{S}}} \varepsilon_{\mathrm{Z}}^{\mathrm{S}}\right) \\
\sigma_{\mathrm{Z}}^{\mathrm{S}}=\Delta\left(\frac{v}{1-v_{\mathrm{S}}} \varepsilon_{\mathrm{r}}^{\mathrm{S}}+\frac{v}{1-v_{\mathrm{S}}} \varepsilon_{\theta}^{\mathrm{S}}+\varepsilon_{\mathrm{Z}}^{\mathrm{S}}\right) \\
\sigma_{\mathrm{rZ}}^{\mathrm{S}}=\Delta\left(\frac{1-2 v_{\mathrm{S}}}{2\left(1-v_{\mathrm{S}}\right)} \varepsilon_{\mathrm{rZ}}^{\mathrm{S}}\right)
\end{array}\right.
$$

where $\Delta=\frac{E_{\mathrm{S}}\left(1-v_{\mathrm{S}}\right)}{\left(1+v_{\mathrm{S}}\right)\left(1-2 v_{\mathrm{S}}\right)}$

Because of the self-weight of granular particles, $\varepsilon_{\theta}^{\mathrm{S}}$ and $\varepsilon_{\mathrm{r}}^{\mathrm{S}}$ are much larger than $\varepsilon_{\mathrm{Z}}^{\mathrm{S}}$, the following equation can be obtained based on Eq. (17).

$$
\left\{\begin{array}{l}
\sigma_{\mathrm{r}}^{\mathrm{S}} \approx \frac{E_{\mathrm{S}} v_{\mathrm{S}}}{\left(1+v_{\mathrm{S}}\right)\left(1-2 v_{\mathrm{S}}\right)} \varepsilon_{\mathrm{r}}^{\mathrm{S}} \\
\sigma_{\mathrm{Z}}^{\mathrm{S}} \approx \frac{E_{\mathrm{S}}\left(1-v_{\mathrm{S}}\right)}{\left(1+v_{\mathrm{S}}\right)\left(1-2 v_{\mathrm{S}}\right)} \varepsilon_{\mathrm{Z}}^{\mathrm{S}}
\end{array}\right.
$$

Considering the elastic state of the storage material in the silo, the lateral pressure coefficient $\mathrm{k}_{2}$ is approximately:

$$
\mathrm{k}_{2}=\frac{\sigma_{\mathrm{r}}^{\mathrm{S}}}{\sigma_{\mathrm{Z}}^{\mathrm{S}}} \approx \frac{v_{\mathrm{S}}}{1-v_{\mathrm{S}}}
$$

For the concrete silo with rigid wall, $\eta \approx 0$ because of $E_{\mathrm{W}} t ? E_{\mathrm{S}} R$. Therefore, when $\eta=0$, Eq. (19) is actually the same as Eq. (16).

Taking Eq. (16) into Eq. (3), the formula for calculating the lateral pressure considering the elasticities of silo wall and bulk particles can be written as

$$
P_{\mathrm{h}}=C_{\mathrm{h}} \gamma \rho\left(1-e^{-\mu \mathrm{k}_{1} s / \rho}\right) / \mu
$$

For shallow silos with aspect ratio between 1.0 and 1.5, Eq. (20) is supposed to be applicable to calculate the lateral pressure. In the following, this paper will utilize the experimental and numerical simulation to compare the above modified lateral pressure calculation by Eq. (20) with the results by Rankine's and Janssen's formulas. Based on silo specification[9], the parameters in the above equations are taken as: $\gamma=8$ $\mathrm{kN} / \mathrm{m}^{3}, \rho=0.25, \mu=0.4, \varphi=25^{\circ}, \mathrm{k}=0.4058, \mathrm{k}_{1}=0.333, C_{\mathrm{h} 0}=1.8, \quad E_{\mathrm{W}}=3 \times 10^{6}$ and $v_{\mathrm{S}}=0.3$, during the theoretical calculation.

\section{Results and Discussions}

\subsection{Experiment verification}


Based on the National Grain Storge in the eastern part of Zhengzhou City, Henan Province, China, the newly-built silos are reinforced concrete shallow circular silos. The diameter(D) of each silo is $28 \mathrm{~m}$, and the height is $36.4 \mathrm{~m}$. The circular shallow silo is well representative. According to the similarity theory[25], the model silo is made of 1:28 ratio reduction of the real-life silo, resulting the diameter and height are 1.0 $\mathrm{m}$ and $1.3 \mathrm{~m}$, and the aspect ratio is 1.3 . The funnel is made of steel, with a diameter of $0.1 \mathrm{~m}$ and an inclination angle of $45^{\circ}$.

Since the organic glass silos are convenient to observe the flow patterns of storage materials and to study the wall normal stresses during silo discharging[14,26-30], the organic glass, whose elastic modulus $(E)$ and Poisson's ratio $(v)$ are $2.758 \times 10^{3}(\mathrm{MPa})$ and 0.29 , respectively[26], is selected to make the model silo. Three columns of sensors $\mathrm{A}, \mathrm{B}$ and $\mathrm{C}$ are arranged along the height direction of the silo wall. The experimental system is shown in Fig.3.

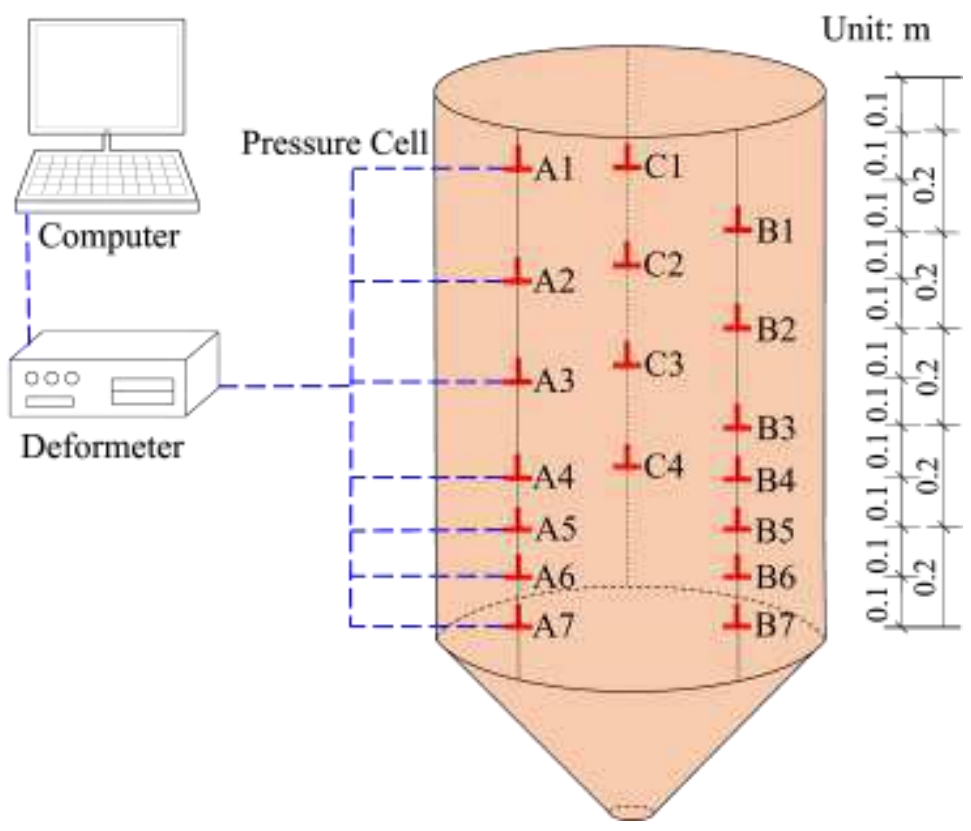

Fig. 3. Schematic diagram of experiment system

The storage materials are wheat, whose physical parameters are given in Tab. 1[9]. Under the same experiment conditions, silo filling and silo discharging are both conducted three times, and the average value of experimental results is adopted.

Table 1. Physical parameters of wheat

\begin{tabular}{ccccccccc}
\hline $\begin{array}{c}\text { Storage } \\
\text { materials }\end{array}$ & $\begin{array}{c}\text { Modulus of } \\
\text { elasticity/GPa }\end{array}$ & $\begin{array}{c}\text { Poisson's } \\
\text { ratio }\end{array}$ & Density $/\left(\mathrm{kN} / \mathrm{m}^{3}\right)$ & $\begin{array}{c}\text { Angle of } \\
\text { repose } /\left(^{\circ}\right)\end{array}$ & Cohesion $/ \mathrm{kPa} a$ & $\begin{array}{c}\text { Internal } \\
\text { friction } \\
\text { angle } /\left({ }^{\circ}\right)\end{array}$ & $\begin{array}{c}\text { Angle of } \\
\text { dilatancy } /\left({ }^{\circ}\right)\end{array}$ & $\begin{array}{c}\text { Coefficient } \\
\text { of friction }\end{array}$ \\
\hline Wheat & 3.0 & 0.3 & 8 & 25 & 300 & 25 & 17.6 & 0.4 \\
\hline
\end{tabular}

The results from three groups of soil pressure sensors are shown in Fig. 4. From 0s to 62s, the storage materials in the silo are static, and the pressure corresponding to the horizontal curves with weak oscillation is the static lateral pressure. After $62 \mathrm{~s}$, the silo discharging begins. Although the stacking height of the storage materials is decreasing, the pressure on the silo wall suddenly increases. When the silo discharging is completed, the curves tend to be stable. The maximum pressure occurs at the initial stage of silo discharging, while the dynamic lateral pressure at the end of the discharging is relatively small. The above results are in accord with the references[31-35], which shows that the designed experiment is reliable. 


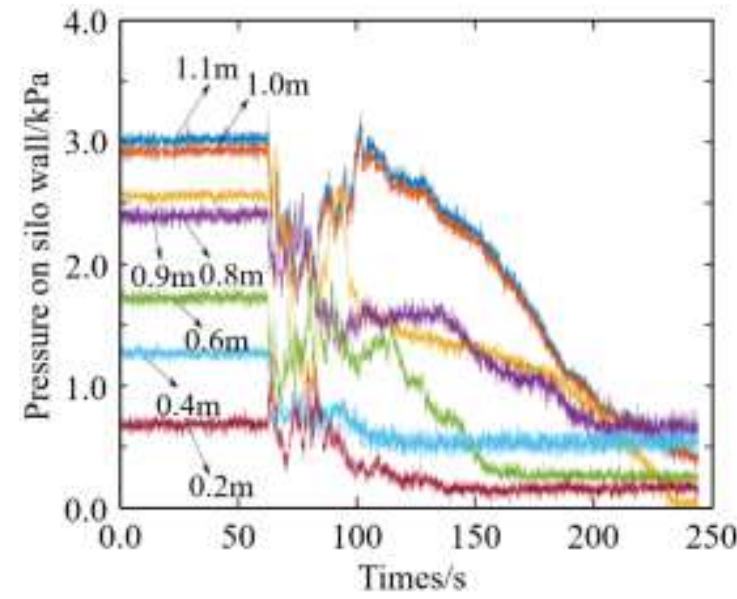

(a) A groups sensors

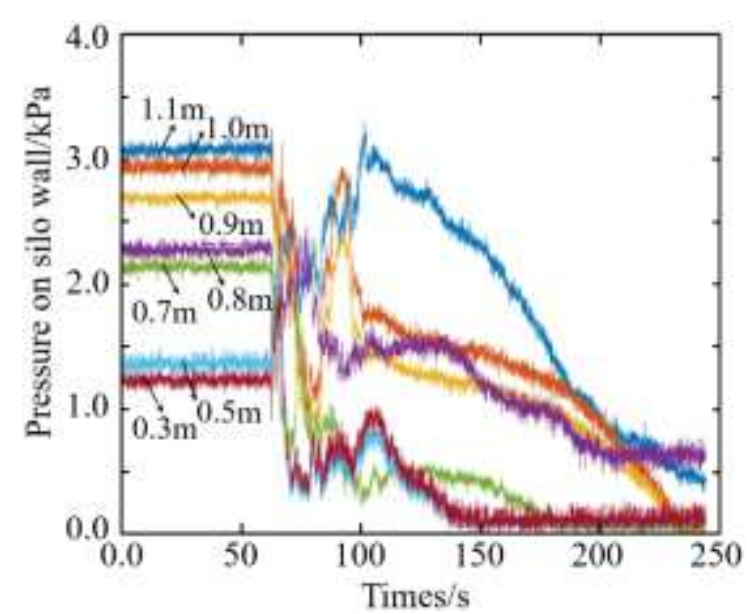

(b) B groups sensors

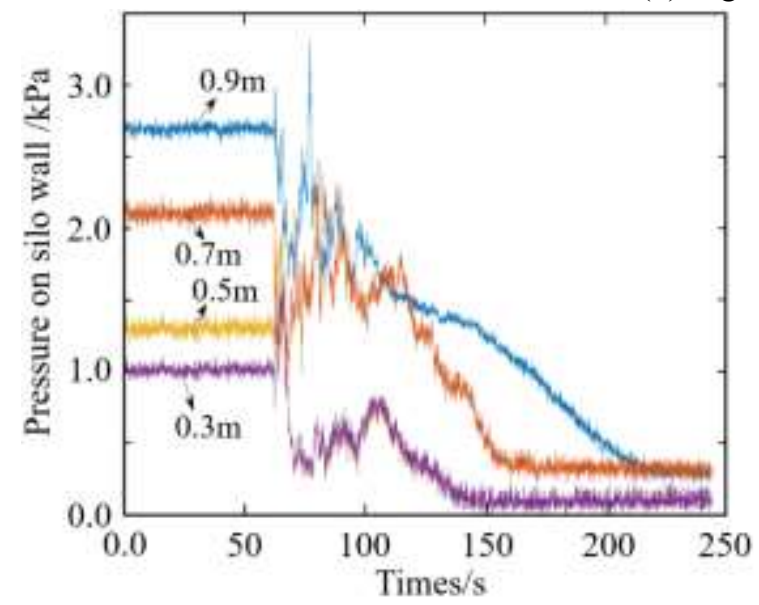

(a) $\mathrm{C}$ groups sensors

Fig. 4. Experiment results

Accordingly, the comparisons of theoretical and the experimental results are shown in Fig. 5. It can be seen from Fig. 5(a) that for the static lateral pressure, the theoretical calculation values at different depths of measuring points are all greater than the experimental values. Therefore, the three theoretical calculation methods all satisfy the safety requirements. However, the maximum value calculated by Rankine's formula is 1.6 times of the experiment and 1.4 times of Janssen's formula. It is too conservative to determine the static lateral pressure according to the specification. The values calculated by the modified method are close to that of Janssen's formula at different depths of measuring points. Therefore, the modified method and Janssen's formula is more suitable for static lateral pressure calculation. It can be seen from Fig. 5(b) that for the dynamic lateral pressure, the values calculated by Janssen's formula are much larger than the experimental value, and the experimental values at all measuring points are greater than the values calculated by Rankine's formula. Therefore, for the dynamic lateral pressure, it is unsafe to calculate the pressure according to the Rankine's formula of shallow circular silo, and it is too conservative to calculate the pressure according to the Janssen's formula of deep silo. By contrast, the results of the modified method are close to and larger than that of the experiments, which is accurate and guarantees the design security at the same time. In addition, for Janssen's formula, the relative error of each measuring point is between $20 \%$ and $30 \%$, which is too large. According to the modified method, the relative error of each measuring point is less than $10 \%$. Therefore, the modified method is the most reliable. 

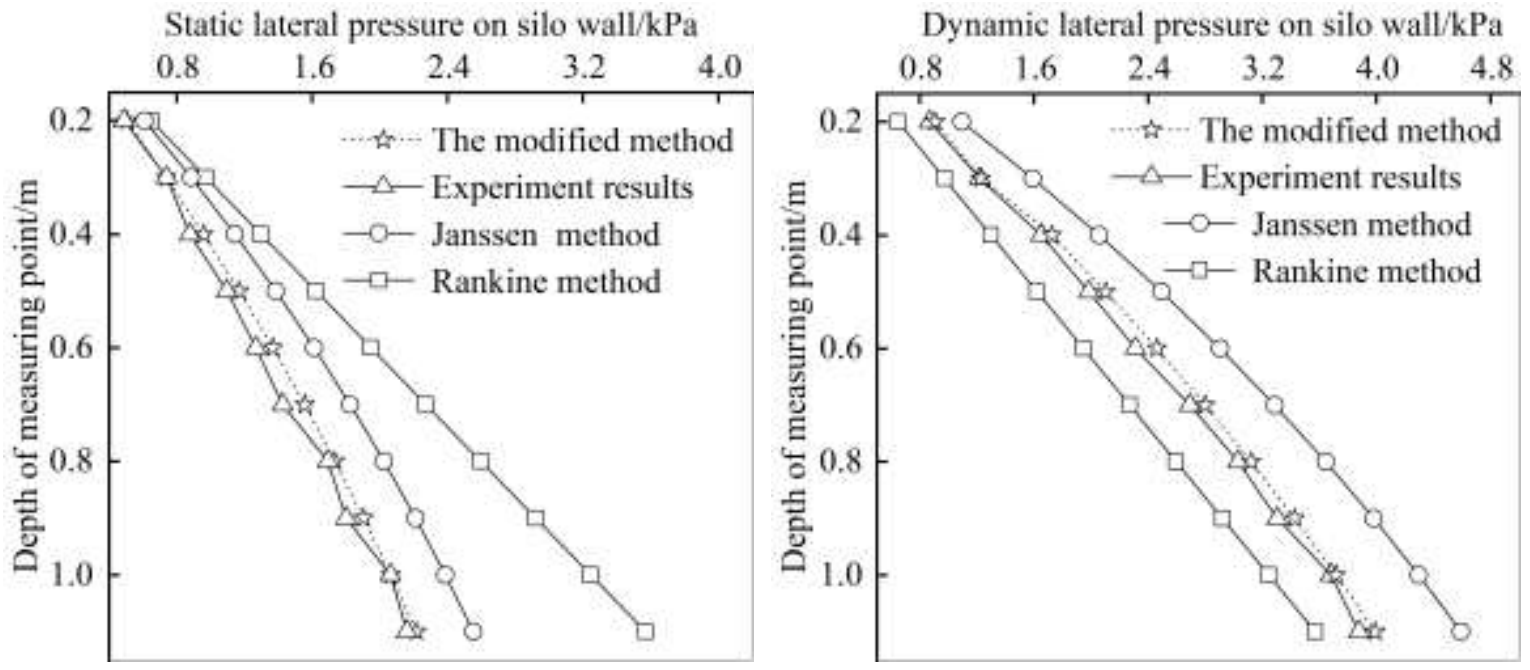

(a)

Fig. 5. Comparisons of the theoretical and the experimental results: (a) the static and (b) the dynamic pressure on the silo wall.

\subsection{Numerical simulation verification}

The investigations about shallow silos with aspect ratios between 1.0 and 1.5 are rarely reported, especially in the experiments. To further verify the applicability of the modified method, the numerical simulation method is utilized to discuss the silos with aspect ratios of 1.1, 1.3 and 1.42 using PFC software. For PFC simulation, it is important to determine the contact stiffness of wall and particle. To obtain the reasonable contact stiffness, a reference value of the contact stiffness of the wall and particles is obtained by using the calculation formula of the contact stiffness, and then the model is repeatedly calibrated through the test results to determine the final value[36]. The detailed calculation steps are as follows: Firstly, the reference values of normal and tangential stiffness of particles are obtained by theoretical calculation. Then, the control variable is used to adjust the reference value continuously, so that the simulated lateral pressure, experimental results and specification values are consistent. Finally, the accurate values of normal and tangential stiffness of particles are obtained. The simulation parameters are shown in Tab. 2.

Tab. 2. Parameters of numerical simulation of silo.

\begin{tabular}{lccccc}
\hline $\begin{array}{c}\text { Normal stiffness } \\
\text { of silo wall }(\mathrm{N} / \mathrm{m})\end{array}$ & $\begin{array}{c}\text { Tangential stiffness } \\
\text { of silo wall }(\mathrm{N} / \mathrm{m})\end{array}$ & $\begin{array}{c}\text { Normal stiffness of } \\
\text { storage } \\
\text { materials }(\mathrm{N} / \mathrm{m})\end{array}$ & $\begin{array}{c}\text { Tangential stiffness of } \\
\text { storage materials }(\mathrm{N} / \mathrm{m})\end{array}$ & $\begin{array}{c}\text { Coefficient of } \\
\text { internal friction }\end{array}$ & $\begin{array}{c}\text { Coefficient of } \\
\text { external friction }\end{array}$ \\
\hline $4 \times 10^{6}$ & $2 \times 10^{6}$ & $1.3 \times 10^{5}$ & $1.0 \times 10^{5}$ & 0.49 & 0.3 \\
\hline
\end{tabular}

The storage particles are generated in layers in the silo using the create ball function, and the unbalanced force is eliminated using the quit and solve functions, to make the storage particles in the silo reach static equilibrium. Then, the results from the silo with aspect ratio of 1.3 are compared with the above experimental results to verify the accuracy of the numerical simulation. The simulation model of silo with an aspect ratio of 1.3 are shown in Fig. 6(a). The comparisons of the experiment and simulation are presented in Fig. 6(b). From Fig. 6(b), it is seen both the static pressure and the dynamic pressure values in simulation match perfectly with the experiment results, which verifies the reliability of the numerical simulation. 


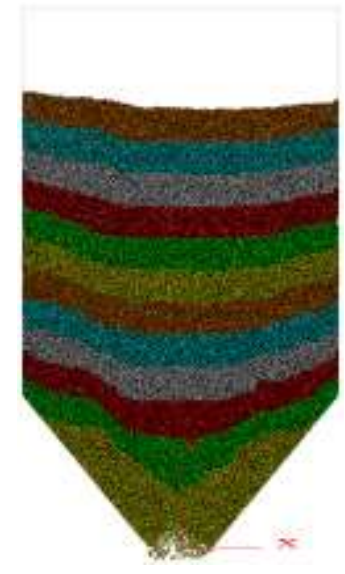

(a)

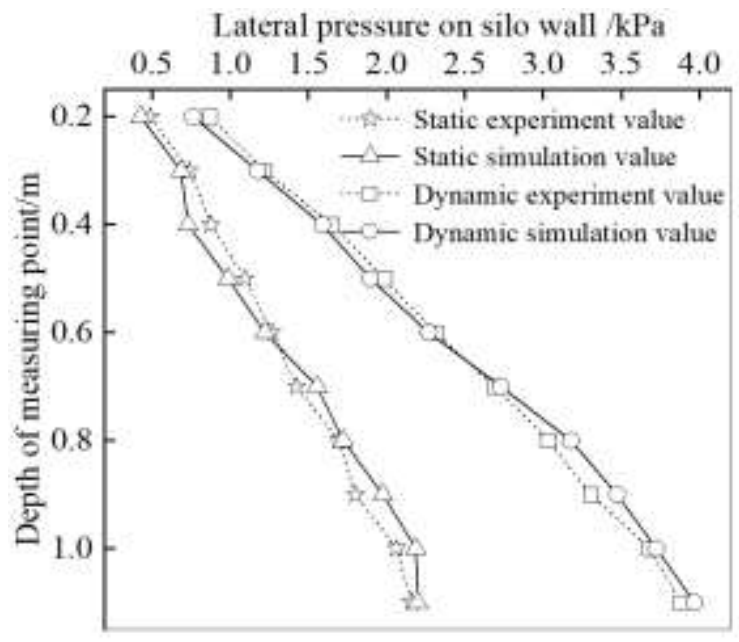

(b)

Fig. 6. (a) Simulation Model and (b) result analysis

For the static lateral pressure on the silos with different aspect ratios, the results of the modified method, Janssen's formula, Rankine's formula and the simulation are compared, as shown in Fig. 7. It can be found that the simulation values are in good agreement with that calculated by the modified method for soil with aspect ratios of 1.1 and 1.42 , and the fluctuation is very small.
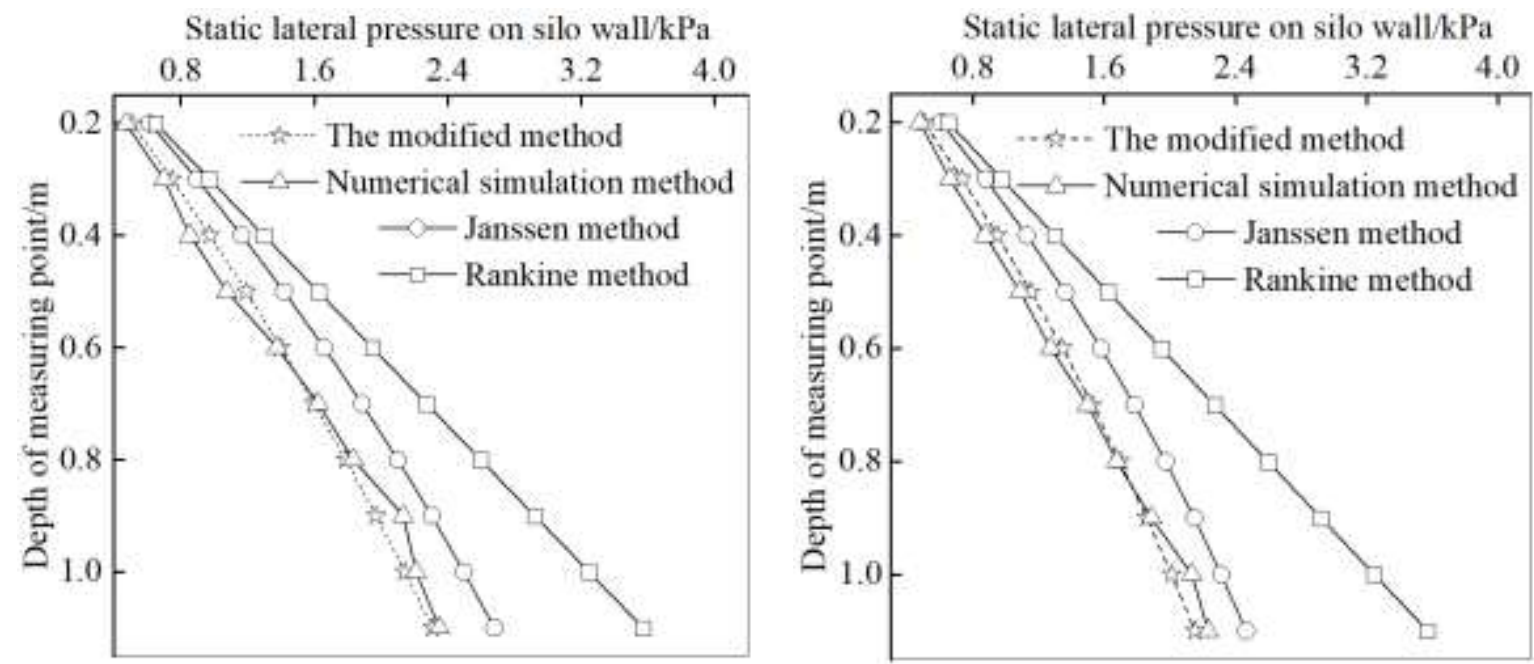

(a)

Fig. 7. Comparison of theoretical values and numerical simulation values of static lateral pressure on soil with aspect ratio of (a) 1.1 and (b) 1.42 .

For the dynamic lateral pressure on the silos with different aspect ratios, calculations by the above theory and the simulation are compared in Fig. 8. It can be seen that the values calculated by Rankine do not meet the design requirements, no matter the aspect ratio is 1.1 or 1.42 . The values calculated by the modified method are in good agreement with that by simulation for soil with aspect ratios of 1.1 and 1.42. 


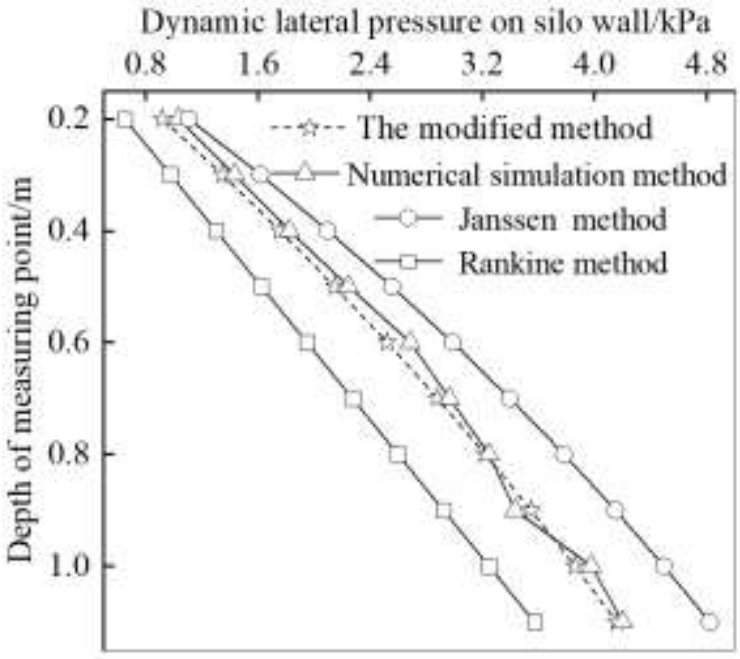

(a) Aspect ratio is 1.1

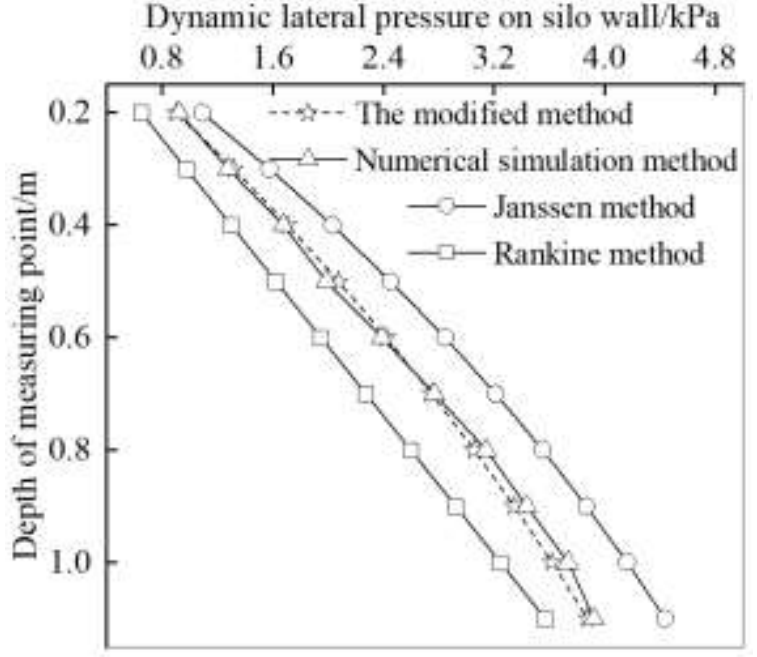

(b) Aspect ratio is 1.42

Fig.8. Comparisons of theoretical values and numerical simulation values of dynamic lateral pressure

In summary, the modified method, which considering the elastic deformations of silo wall and storage materials, is valid for predicting the lateral pressure on the silos with aspect ratio between 1.0 and 1.5, and thus is recommended for the design of the shallow silos with aspect ratio between 1.0 and 1.5.

\section{Conclusions}

This paper analyzed the shortcomings of the lateral pressure calculation of shallow circular silo with aspect ratio between 1.0 and 1.5 in the specification based on Rankine and Janssen theories. Considering the influence of elastic deformations of silo wall and storage materials, a modified method for calculating lateral pressure was proposed for the design of silos with aspect ratio between 1.0 and 1.5. The effectiveness of this method is verified by experiments and numerical simulations. The main conclusions are as follow:

(1) When checking the load under silo discharging, the dynamic pressure calculation of shallow circular silo based on Rankine theory is not safe. While the calculation of deep silo based on Janssen theory is conservative, and the relative error of each measuring point is between $20 \%$ and $30 \%$, which is too large.

(2) The static and dynamic results based on the proposed modified method are both in good agreement with the experimental and numerical simulations. It is proved that the modified lateral pressure calculation method is a good choice for shallow silos with aspect ratio between 1.0 and 1.5, which can provide a reliable theoretical basis for further improving the design of silo.

\section{Acknowledgment}

The research is partially supported by the Key Laboratory of Grain and Oil Storage Construction and Safety in Henan Province under Grant No. 2021KF-A01. Besides, the authors would like to express their sincere gratitude to National Natural Science Foundation of China under Grant No. 51578216.

\section{Declaration of Competing Interest}

The authors declare that there is no conflict of interest.

\section{Credit authorship contribution statement}


Conceptualization, Z.X. and P.L.; methodology, Z.X. and P.L.; software, P.L.; validation, Z.X. and H.Y.; formal analysis, Z.X.; investigation, Z.X. and P.L.; resources, Z.X.; data curation, P.L.; writing-original draft preparation, Z.X. and P.L.; writing-review and editing, Z.X. and P.L.; visualization, Z.X. and P.L.; supervision, Z.X.; project administration, Z.X.; funding acquisition, Z.X. All authors have read and agreed to the published version of the manuscript.

\section{References}

[1] Chen, Y, Y., Liang, C., Wang, X., Guo, X, Q. Static pressure distribution characteristics of powders stored in silos. Chemical Engineering Research \& Design, 2020,154(5): 1-10.

[2] Guo, J., Roberts, A. W., Prigge, J, D. Experimental investigation of wall pressure and arching behavior under surcharge pressure in mass-flow hoppers. Powder Technology, 2014, 258(5): 272-284.

[3] Couto, A., Ruiz, A., Aguado, P, J. Experimental study of the pressures exerted by wheat stored in slender cylindrical silos, varying the flow rate of material during discharge. Comparison with Eurocode 1 part 4. Powder Technology, 2013, 237: 450-467.

[4] Ding, S., Li, H., Ooi, J, Y., Rotte, J, M. Prediction of flow patterns during silo discharges using a finite element approach and its preliminary experimental verification. Particuology, 2015, 18(2): 42-49.

[5] Mathews, J, C., Wu, W. Model tests of silo discharge in a geotechnical centrifuge. Powder Technology, 2016, 293(5): 3-14.

[6] Carson, J, W., Holmes, T. Silo failures: why do they happen?. Task Quarterly, 2003, 7(4): 499-512.

[7] Dogangun, A., Karaca, Z., Durmus, A., Sezen, M. Cause of Damage and Failures in Silo Structures. Journal of performance of constructed facilities, 2009, 23(2): 65-71.

[8] EN 1991-4(2006), Eurocode 1: Basis of design and actions on structures, part 4-silos and tanks, CEN, Brussels, 2007.

[9] Ministry of Housing and Urban-Rural Development of the People's Republic of China. Standard for design of reinforced concrete silos (GB50077-2017). Beijing: China Planning Press Co., Ltd., 2018.

[10] Rabinovich, E., Kalman, H., Peterson, P, F. Parametric study and design procedure for planar silos and hoppers. Powder Technology, 2021, 377(2): 333-342.

[11] Yang, Z, Y., Liu, S, H., Zhao, S., Hu, J. Study on Silo Pressure by Consider Storage Materials Density Changed along the Height. Pro of Novel and non-conventional materials and technologies for sustainability, Changsha, 2011: 797-800.

[12] Sun, Y, F., Song, S, X., Xiao, Y., Zhang, J, C. Development and application of state-dependent fractional plasticity in modeling the non-associated behavior of granular aggregates. Acta Mechanica Solida Sinica, 2017, 30(5): 507-519.

[13] Kobylka, R., Molenda, M. DEM simulations of loads on obstruction attached to the wall of a model grain silo and of flow disturbance around the obstruction. Powder Technology, 2014, 256(4): 210-216.

[14] Wang, X., Liang, C., Guo, X., Chen, Y, Y. Experimental study on the dynamic characteristics of wall normal stresses during silo discharge. Powder Technology, 2020, 363(3): 509-518.

[15] Kobyłka, R., Horabik, J., Molenda, M. Numerical simulation of the dynamic response due to discharge initiation of the grain silo. International Journal of Solids and Structures, 2017, 106-107(2): 27-37.

[16] Askif, F., Hammadeh, H., Ubysz, A., Maj, M. Numerical Modeling of Wall Pressure in Silo with and Without Insert. Studia Geotechnica et Mechanica, 2020, 43(1): 1-12.

[17] Horabik, J., Molenda, M. Mechanical Properties of Granular Materials and Their Impact on Load Distribution in Silo: A Review. Scientia Agriculturae Bohemica, 2014, 45(4): 203-211.

[18] Patel, C, P., Kute, S. Prediction of wall pressures and stresses developed by grainy materials in 
cylindrical ferrocement silo in static condition. Asian Journal of Civil Engineering, 2021, 22(7): 12351248.

[19] Lei, Y, S., Ma, Q, W., Shi, Q, F. Side-wall pressure distribution of cylindrical granular containers with flat bottom. Powder Technology, 2019, 353(7): 57-63.

[20] An, H, Q., Wang, X., Fang, X, H., Liu, Z., Liang, C. Wall normal stress characteristics in an experimental coal silo. Powder Technology, 2021, 377(2): 657-665.

[21] Wójcik, M., Sondej, M., Rejowski, K. Full-scale experiments on wheat flow in steel silo composed of corrugated walls and columns. Powder Technology, 2017, 311(4): 537-555.

[22] Huang, H, R., Wang, J, W., Dong, R, R. Academic study on wall pressure of grain silo with shallow circle shape. Journal of environmental protection and ecology, 2019, 20(1): 285-291.

[23] Gao, X., Zou, Y., Zhou, X. Bucking analysis under combined loading of thin-walled plate assemblies using bubble functions. Acta Mechanica Solida Sinica, 2000,13: 125-133.

[24] Chen, C, Q., Cui, J, Z., Duan, ..., Zou, W, N. Perspectives in mechanics of heterogeneous solids. Acta Mechanica Solida Sinica, 2011, 24(1): 1-26.

[25] Iai, S. Similitude for Shaking Table Tests on Soil-Structure-Fluid Model in 1g Gravitational Field. Soils and foundations, 1989, 29(1): 105-118.

[26] Matchett, A, J. The shape of the cohesive arch in hoppers and silos-Some theoretical considerations. Powder Technology, 2007, 171(3): 133-145.

[27] Hidalgo, R, C., Lozano, C., Zuriguel, I., Garcimartin, A. Force analysis of clogging arches in a silo. Granular Matter, 2013, 15(6): 841-848.

[28] Jiang, M, Z., Tsai, J, C., Yang, F, L. Measurement of boundary force and wall friction coefficient during the development of a granular discharge flow from a symmetric silo. Journal of the Chinese Institute of Engineers, 2021, 44(4): 368-378.

[29] Liu, H, R., Han, Y, L., Jia, F, G., Zhao, H. An experimental investigation on jamming and critical orifice size in the discharge of a two-dimensional silo with curved hopper. Advanced Powder Technology, 2020, 32(1): 88-98.

[30] Zou, Z, Ruyer P, Lagree P Y, Ausslillous P. Discharge of a silo through a lateral orifice: Role of the bottom inclination versus friction. Physical review. E, 2020, 102(5-1): 052902.

[31] Abdel-Fattah, M, T., Moore, I, D., Abdel-Fattah T T. A numerical investigation into the behavior of ground-supported concrete silos filled with saturated solids. International Journal of Solids and Structures, 2005, 43(13): 3723-3738.

[32] Goodey, R, J., Brown, C, J., Rotter, J, M. Rectangular steel silos: Finite element predictions of filling wall pressures. Engineering Structures, 2016, 132(1): 61-69.

[33] Kobyłka, R., Molenda, M., Horabik, J. DEM simulation of the pressure distribution and flow pattern in a model grain silo with an annular segment attached to the wall. Biosystems Engineering, 2020, 193(5): 75-89.

[34] Wang, P, J., Li, Z., Zhu, X, L. Flow pattern and normal pressure distribution in flat bottom silo discharged using wall outlet. Powder Technology, 2016, 295(7): 104-114.

[35] Wang, Y., Lu, Y., Ooi, J, Y. A numerical study of wall pressure and granular flow in a flat-bottomed silo. Powder Technology, 2015, 282(9): 43-54.

[36] Farouk, H., Farouk, M. Soil, Foundation, and Superstructure Interaction for Plane Two-Bay Frames. International Journal of Geomechanics, 2014, 16: B4014003. 